Artículo científico

(Original paper)

\title{
THREE NEW SPECIES OF PROPARACHAETA TOWNSEND, 1928 (DIPTERA: TACHINIDAE) FROM BRAZIL AND PERU, AND REDESCRIPTION OF THE TYPE SPECIES FROM PARAGUAY
}

\section{TRES NUEVAS ESPECIES DE PROPARACHAETA TOWNSEND, 1928 (DIPTERA: TACHINIDAE) DE BRASIL Y PERÚ, Y REDESCRIPCIÓN DE LA ESPECIE-TIPO DE PARAGUAY}

\author{
RONALDO TOMA \\ Fiocruz - Mato Grosso do Sul, Rua Gabriel Abrão, 92, Jardim das Nações, Campo Grande, MS, Brasil, Cep: 79081-746. \\ <rtkuna1@gmail.com> \\ *Autor de correspondencia: <rtkuna1@gmail.com> \\ Recibido: 27/09/2018; aceptado: 16/08/2019; publicado en línea: 20/08/2019 \\ Editor responsable: Sergio Ibáñez Bernal
}

Toma, R. (2019) Three new species of Proparachaeta Townsend, 1928 (Diptera: Tachinidae) from Brazil and Peru, and redescription of the type species from Paraguay. Acta Zoológica Mexicana (nueva serie), 35, 1-13. https://doi.org/10.21829/azm.2019.3502079

\begin{abstract}
Four species of Proparachaeta Townsend (Goniini) are recognized in the Neotropical Region: the type species $P$. paraguayensis Townsend, 1928, from Paraguay, Proparachaeta niheii sp. $\mathrm{n}$. from Brazil, Proparachaeta punensis sp. n. from Peru and Proparachaeta rondonensis sp. n. from Brazil. The type species is redescribed and the three new species are described and illustrated. A key is provided for the identification of the four species.
\end{abstract}

Key words: Exoristinae; Goniini; Neotropical; Proparachaetopsis; taxonomy

Toma, R. (2019) Tres nuevas especies de Proparachaeta Townsend, 1928 (Diptera: Tachinidae) de Brasil y Perú, y redescripción de la especie-tipo de Paraguay. Acta Zoológica Mexicana (nueva serie), 35, 1-13. https://doi.org/10.21829/azm.2019.3502079

RESUMEN. Cuatro especies de Proparachaeta Townsend, 1928 son reconocidas en la región Neotropical, incluyendo tres nuevas especies: Proparachaeta niheii sp. n., Proparachaeta punensis sp. n. y Proparachaeta rondonensis sp. n. Se redescribe la especie-tipo del género Proparachaeta, Proparachaeta paraguayensis Townsend, 1928, y se describen e ilustran las especies nuevas. Se proporciona una clave para la identificación de las cuatro especies.

Palabras clave: Exoristinae; Goniini; Neotropical; Proparachaetopsis; taxonomía 


\section{INTRODUCTION}

Proparachaeta paraguayensis was proposed as a new genus and species by Townsend (1928). The species was described from one male from Paraguay, which was sent to Townsend by Dr. Walther Horn at the Deutsches Entomologisches Institut collection, where the holotype was subsequently housed. Since then, this genus has been represented by only this one species.

Townsend (1936; 1941) placed Proparachaeta in the tribe Harrisiini. Guimarães (1971) followed this classification and considered the genus Proparachaetopsis Blanchard, 1942, as a new synonym of Proparachaeta. Toma and Guimarães (2000) removed Proparachaetopsis from synonymy and recognized it as a valid genus based on the row of setulae on its parafacial. Several genera belonging to the now invalid tribe Harrisiini were placed in Goniini (Exoristinae) by O'Hara and Wood (2004) and Toma and Nihei (2006). Following these authors, Proparachaeta is placed in Goniini herein. This tribe consists of species whose females lay huge numbers of microtype eggs on foliage, which are subsequently eaten by the host. This characteristic has been hypothesized as a derived state within Tachinidae and has been used to define the tribe Goniini (Herting, 1984; Wood, 1987; Cerretti et al., 2014).

An undetermined Proparachaeta species was catalogued by Guimarães (1977) as a parasitoid of lepidopteran larvae of Ammalo helops (Cramer, 1776) (Erebidae) and Dysschema sacrifica (Hübner, 1831) (Erebidae).

Based on the examination of the holotype of $P$. paraguayensis and new material from Mato Grosso, Rondônia (Brazil), and Puno (Peru), this study provides redescriptions of Proparachaeta and its type species, description of three new species and a key to the four included species.

\section{MATERIALS AND METHODS}

This study was based on material housed at the Museu de Zoologia, Universidade de São Paulo (MZUSP), Brazil, including material collected by the Project SISBIOTA-Diptera, and on the P. paraguayensis holotype housed at the Deutsches Entomologisches Institut (DEI), Germany. The SISBIOTA-Diptera project was financed by the National Council for Scientific and Technological Development (CNPq) and São Paulo Research Foundation (FAPESP) and coordinated by Dr. Carlos Lamas (MZUSP) and Dr. Silvio Nihei (Instituto de Biociências, Universidade de São Paulo (IB-USP), Brazil).

Terminology used for morphological structures follows Cumming and Wood (2017), except the terms hypandrial apodeme and hypandrial middle plate taken from Tschorsnig (1985). Head measurements follow Toma and Guimarães (2002). Digital images and illustrations were prepared using a Zeiss Stemi 508 stereoscope microscope with a coupled AmScope MU300 3.0 MP digital camera and then mounted on plates using Image Manipulation Program - Gimp v. 2.8.

For examination of male terminalia, pinned specimens were placed into $70 \%$ ethanol for five minutes, then removed from the pin for dissection of the terminalia. After removal of terminalia, the specimens were again pinned, and the terminalia were put into $10 \%$ potassium hydroxide at room temperature for 24 hours, placed into acetic acid for 10 minutes, washed in distilled water for 10 minutes, dehydrated in an alcoholic series, then put into glycerin. After examination, terminalia were stored in plastic microvials with glycerin. Specimen label data are listed in the top-down order they appear on the pin; quotation marks enclose data from each label, a diagonal slash (/) demarcates label line, and square brackets enclose additional information not appearing on a label. 


\section{RESULTS AND DISCUSSION}

\section{Taxonomy}

\section{Proparachaeta Townsend, 1928}

Proparachaeta Townsend, 1928: 152. Type-species: Proparachaeta paraguayensis Townsend, 1928, by original designation. Townsend (1936) (key to Harrisiini genera-page 189); Townsend (1941) (diagnosis-page 82).

Redescription (male only) (Figs: 1-18). Head. Eye bare; arista bare; ocellar seta proclinate, short or weak; outer vertical seta reduced, indistinguishable from postocular seta; frontal setae descending to level of upper third of parafacial, flanked by irregular row of shorter setae; fronto-orbital plate with short and thin setulae from vertex level to lowermost frontal seta; one reclinate orbital seta; proclinate orbital seta absent; parafacial bare except for a few hairs below lowest frontal seta; arista tapering smoothly to apex; first aristomere short; second aristomere slightly longer than wide; vibrissa stout, inserted above level of lower facial margin; palpus clavate, slightly bowed on apical third and slightly longer than prementum; lower facial margin slightly projected; genal dilation covered with thin black setulae. Thorax. Acrostichal setae $3+3$; dorsocentral setae $3+4$; intra-alar setae $2+3$, the anterior presutural intra-alar seta close to postpronotal lobe, the posterior presutural intra-alar seta close to transverse suture, and two extra setae flanking posterior inner side of postpronotal lobe; supra-alar setae $1+3$ or $1+4$; three postalar setae; intrapostalar seta shorter than posterior postalar seta; postpronotal lobe with four setae: three basal postpronotal setae almost in line and one weaker anterior postpronotal seta usually in front of inner postpronotal seta; scutum in posterodorsal view with five dark brown stripes: two outside of the dorsocentral rows, two outside of the acrostichal rows and one between acrostichal rows; katepisternum with three to six setae; wing subhyaline with basal fourth infuscate; cell $\mathrm{r}_{4+5}$ open with $\mathrm{R}_{4+5}$ and vein $\mathrm{M}_{1}$ ending anterior to wing apex; apical section of vein $\mathrm{M}_{1}$ bent sharply forward; hind tibia with a comb-like row of anterodorsal setae, each seta separated from adjacent setae by no more than its own width. Abdomen. Abdominal syntergite $1+2$ and tergite 3 without median marginal setae; tergites 4 and 5 with a row of median marginal setae; discal setae lacking on syntergite $1+2$ and tergites 3 and 4; abdominal setulae gradually increasing in size posteriorly, more visible on sides of the tergites 4 and 5. Male terminalia (Figs. 9-18). Tergite 6 divided into two very small plates, spiracles situated laterally on membrane; sternite 6 asymmetric and narrow, its left margin wider than the right margin, both margins connected to segment $7+8$, its hind margin with two protrusions; sternite 5 with median cleft $\mathrm{U}$ shaped; epandrium in lateral view with anterodorsal margin short and slightly convex, posterior dorsolateral and ventrolateral margins extending into a subtriangular lobe, ventral margin sinuous; anterior epandrial extension developed, slightly shorter than anterodorsal margin; hypandrial apodeme in ventral view moderately elongated and slightly narrower than hypandrial middle plate; line between hypandrial apodeme and hypandrial middle plate less sclerotized; hypandrial arms relatively short and fused; pregonite almost straight and slightly parallel-sided, tapering subapically, its apex slightly turned outward and downward; postgonite tapering and slightly curved downward and smaller and narrower than pregonite; basiphallus slightly bent upward; epiphallus reduced, short; distiphallus slightly curved downward; acrophallus broad; cercus in lateral view beak-shaped, with a protuberance between the cerci in the middle of the anterior surface, and in posterior view tapered from base to apex; in lateral view surstylus almost straight throughout its length, with slightly parallel-sided margins and rounded apex.

Remarks. Toma and Guimarães (2000) suggested that Proparachaeta and Proparachaetopsis might be related genera based on shared similarities of the male terminalia, such as cercus beak-shaped in lateral view, aedeagus with broad acrophallus and basiphallus slightly bent upward, and hypandrial arms fused, but Proparachaeta differs from the latter by parafacials bare on basal two-thirds, postpronotal lobe with three basal postpronotal setae almost in line and one weaker anterior postpronotal seta usually in front of inner postpronotal seta, surstylus in lateral view almost straight throughout its length with margins slightly parallel-sided and apex rounded, and pregonite tapered subapically (for comparison see Toma and Guimarães 2000: Figs. 4-21). 
Toma: New species of Proparachaeta Townsend, 1928
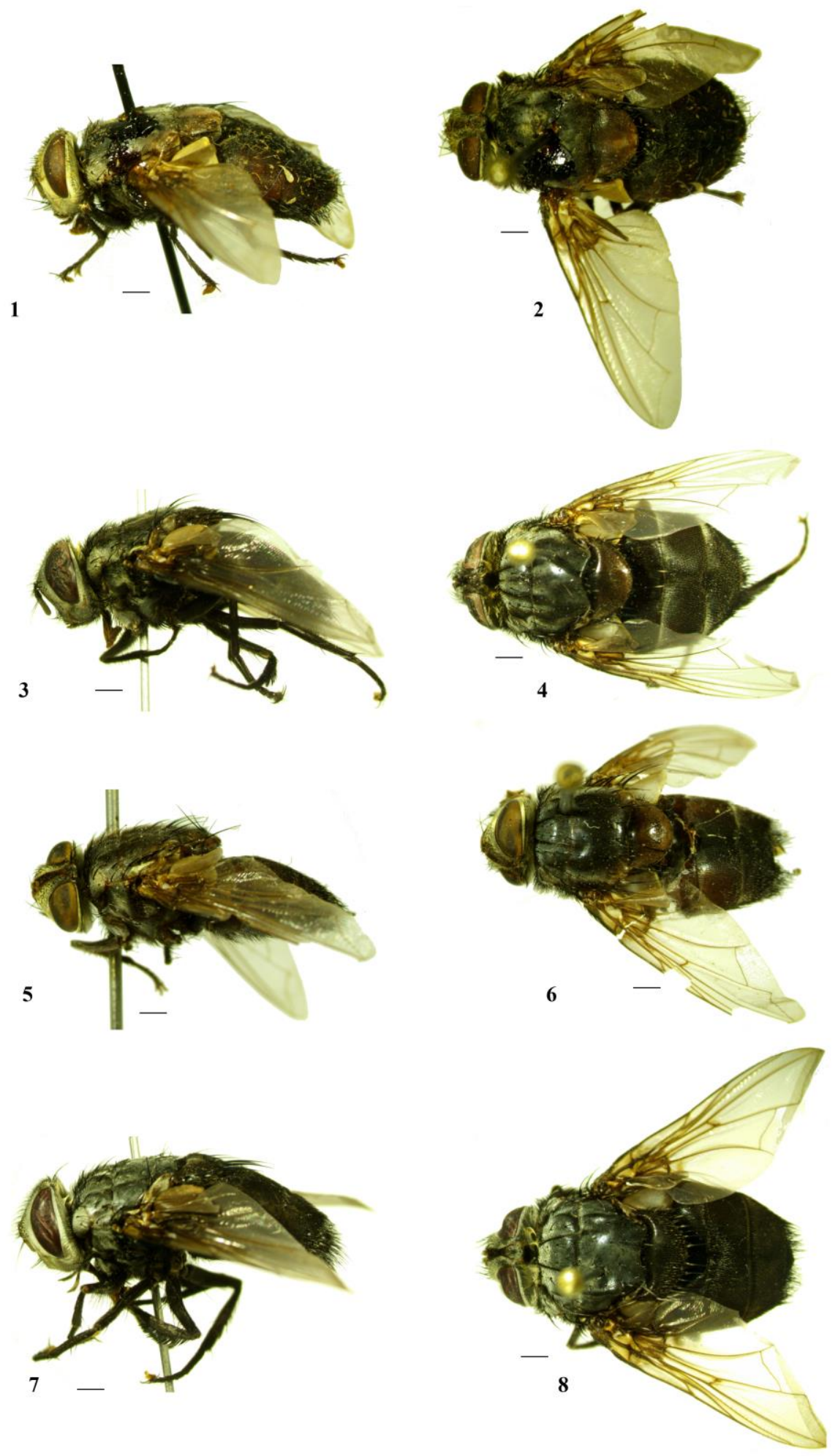

Figures 1-8. Male habitus, lateral and dorsal views (scale bar $1 \mathrm{~mm}$ ): 1-2, Proparachaeta paraguayensis; 3-4, $P$. niheii sp. n.; 5-6, P. punensis sp. n.; P. rondonensis sp. $\mathrm{n}$. 
The postpronotal lobes with three basal postpronotal setae almost in line and one anterior postpronotal seta in front of inner postpronotal seta has only been observed in Proparachaeta when compared to other members of the invalid tribe Harrisiini and therefore should be tested as a putative synapormorphy of its species in future phylogenetic studies.

\section{Key to separate Proparachaeta from Proparachaetopsis}

1. Parafacial bare on basal two-thirds; postpronotal lobe with three postpronotal setae almost in line and one weaker anterior postpronotal seta usually in front of inner postpronotal seta; surstylus in lateral view almost straight throughout its length with margins slightly parallel-sided and apex rounded (Figs. 11-14) ......

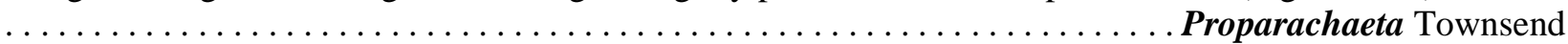
- Parafacial with a row of setulae on basal two-thirds, flanked by shorter setulae; postpronotal lobe with three postpronotal setae almost in line and one weaker anterior postpronotal seta positioning between the middle and inner postpronotal setae; surstylus in lateral view sharper (see Toma and Guimarães 2000: Figs.

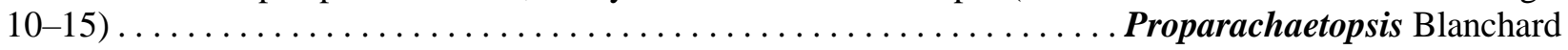

\section{Key to species of Proparachaeta (adult males only)}

1. Four postsutural supra-alar setae . . . . . . . . . . . (Peru: Puno) Proparachaeta punensis sp. n.

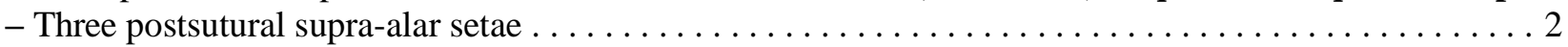
2. Upper and lower calypters brown with very short hairs of the same colour on margin; abdomen covered with brown pruinosity; the longest mid tibial anterodorsal seta about $0.2 x$ length of tibia $\ldots \ldots \ldots \ldots \ldots \ldots \ldots \ldots \ldots \ldots \ldots \ldots \ldots \ldots \ldots \ldots \ldots$ (Brazil: Rondônia) Proparachaeta rondonensis sp. $n$. - Upper and lower calypters yellow or light yellow with very short hairs of the same colour on margin; abdomen not as above; the longest mid tibial anterodorsal seta about one-third length of tibia ........3 3. Cercus in lateral view with basal two-thirds relatively robust and apical third short (Fig. 12); scutellar dorsum brown pruinose . . . . . . . . . . . . . (Brazil: Mato Grosso) Proparachaeta niheii sp. n. - Cercus in lateral view with basal two-thirds less robust and apical third more elongated (Fig. 11); scutellar dorsum moderate grey to light brownish grey pruinose when viewed from certain angles . . . . . . . . .

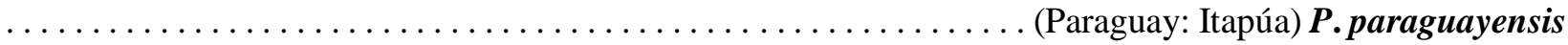

\section{Proparachaeta paraguayensis Townsend, 1928}

(Figures 1, 2, 11, 15)

Proparachaeta paraguayensis Townsend, 1928: 152, type locality: Sta. (= Santa) Trinidad, Paraguay. Guimarães (1971) (catalogue-page 186).

Type material. Holotype male (DEI-Müncheberg), labelled: "Paraguay / Sa. Trinidad / vi.1914 [numbers 'vi' and '14' handwritten]"; "Proparachaeta paraguayensis / TT / male symbol / Det CHTT [handwritten except Det CHTT]"; "Townsend det"; "88 [handwritten]"; "Type [red label]"; "Holotypus [red label]"; "DEI-Müncheberg / Dip-00156 [green label]". [Type material in good condition, except for some missing setae and not well preserved abdominal pruinosity. Unfortunately, terminalia were lost after being examined and drawn].

Diagnosis. Head covered with yellow pruinosity, except upper two-thirds of facial ridge yellowish-grey pruinose; ocellar seta short but well differentiated from ocellar triangle setulae; scutellar dorsum moderate grey to light brownish-grey pruinosity when viewed from certain angles; calypters yellow with faint yellow pruinosity; abdomen in posterodorsal view reddish-brown except most of syntergite 1+2 and middle of tergites 3 and 4 dark brown. 
Description. Male. Body length: $13.5 \mathrm{~mm}$, wing length: $12.3 \mathrm{~mm}$.

Coloration. Vertex, frontal vitta and ocellar triangle brown with brown pruinosity; head covered with yellow pruinosity, except upper two-thirds of facial ridge yellowish-grey pruinose; occiput with pale creamcoloured hairs; lunule and scape yellowish; pedicel and flagellomere brown, but light reddish between segments; palpus and proboscis reddish-brown; thorax dark brown in ground colour except reddish-brown on scutum laterally, postalar callus and part of anepimeron; thorax with moderate grey pruinosity except postpronotal lobe, scutum laterally, postalar callus and anepisternum moderate yellowish-grey pruinose; scutellar dorsum reddish-brown with moderate grey to light brownish-grey pruinosity when viewed from certain angles; legs brown; wing hyaline; veins light reddish-brown; wing stalk which contains the bases of the main veins is lighter; calypters yellow with faint yellow pruinosity, very short hairs of the same colour on margin; abdomen in posterodorsal view reddish-brown except most of syntergite 1+2 and middle of tergites 3 and 4 dark brown; abdomen in ventral view reddish-brown (abdominal pruinosity not well preserved in the holotype). Head. Vertex about $0.2 \mathrm{x}$ head width in dorsal view; inner vertical seta and reclinate orbital seta developed (both damaged in the type material); ocellar setae short but well differentiated from ocellar triangle setulae; fronto-orbital plate with about 12 frontal setae, two of them situated below lower margin of pedicel; fronto-orbital plate almost as wide as parafacial; first flagellomere length about $1.5 x$ length of pedicel; pedicel about $2.8 x$ length of scape; third aristomere about $1.7 x$ length of first flagellomere; facial ridge with a row of stout supravibrissal setae on lower 0.4 of its length, setae $0.2-0.5 x$ length of vibrissa; anteroventral margin of gena with a row of setae extending backward, setae $0.3-0.45 x$ length of vibrissa. Thorax. Acrostichal setae $3+3$, with posteriormost postsutural seta longer and about $1.8 \mathrm{x}$ length of the preceding seta; dorsocentral setae $3+4$, with posteriormost postsutural seta longer and about $1.7 x$ length of the preceding seta; intra-alar setae $2+3$, with posteriormost postsutural seta longer and about 2.1x length of the preceding seta; the posteriormost presutural intra-alar seta missing (its socket remaining); supra-alar setae $1+3$, with the second and third postsutural setae longer, each about $1.7 x$ length of first postsutural seta; three postalar setae, the second seta longer and stronger, about $2.2 \mathrm{x}$ length of the third seta; katepisternum with five setae: the anterior and posterior setae longer and stronger, two anteroventral setae, one more ventral, stouter and closer to anterior katepisternal seta, the other situated more posteriorly, one posteroventral almost aligned with anterior and posterior katepisternal setae; scutellum with one pair of basal, three pairs of lateral (first lateral seta more ventrally positioned), one pair of subapical, one pair of apical (tiny and almost undistinguishable from setulae on the scutellar dorsum) and one pair of discal setae; mid tibia with three strong anterodorsal setae, the longest about $0.3 \mathrm{x}$ length of tibia; hind tibia with an irregular row of posterodorsal setae, three to four setae longer, the longest shorter than the longest seta of the anterodorsal row. Terminalia (Figs. 11, 15). Epiphallus reduced; cercus in profile anteriorly almost entirely straight and gently curved backward subapically, with anterior protuberance between cerci in the midlength small, posteriorly slightly concave at midlength and rounded subapically; cerci in posterior view subtriangular, with lateral edges almost in a straight line.

Female. Unknown.

Geographic distribution. Paraguay (Itapúa: Santa Trinidad).

Remarks. Proparachaeta paraguayensis resembles $P$. niheii sp. $\mathrm{n}$., sharing with it the following combination of characteristics: head with yellow or yellowish-grey pruinosity, occiput with pale creamcoloured hairs, three postsutural supra-alar setae, and yellow calypters. Proparachaeta paraguayensis differs from $P$. niheii sp. n. by ocellar seta short but well differentiated from ocellar triangle setulae, scutellar dorsum with moderate grey to light brownish grey pruinosity when viewed from certain angles, cercus in profile with basal two-thirds less robust, apical one-third slightly longer, anterior protuberance between cerci in the midlength smaller, and cerci in posterior view with lateral edges straighter. 

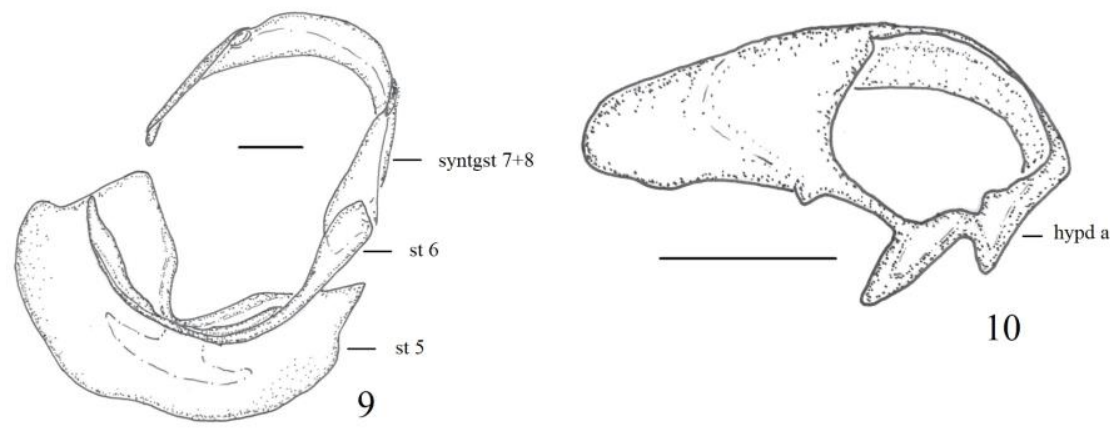

10
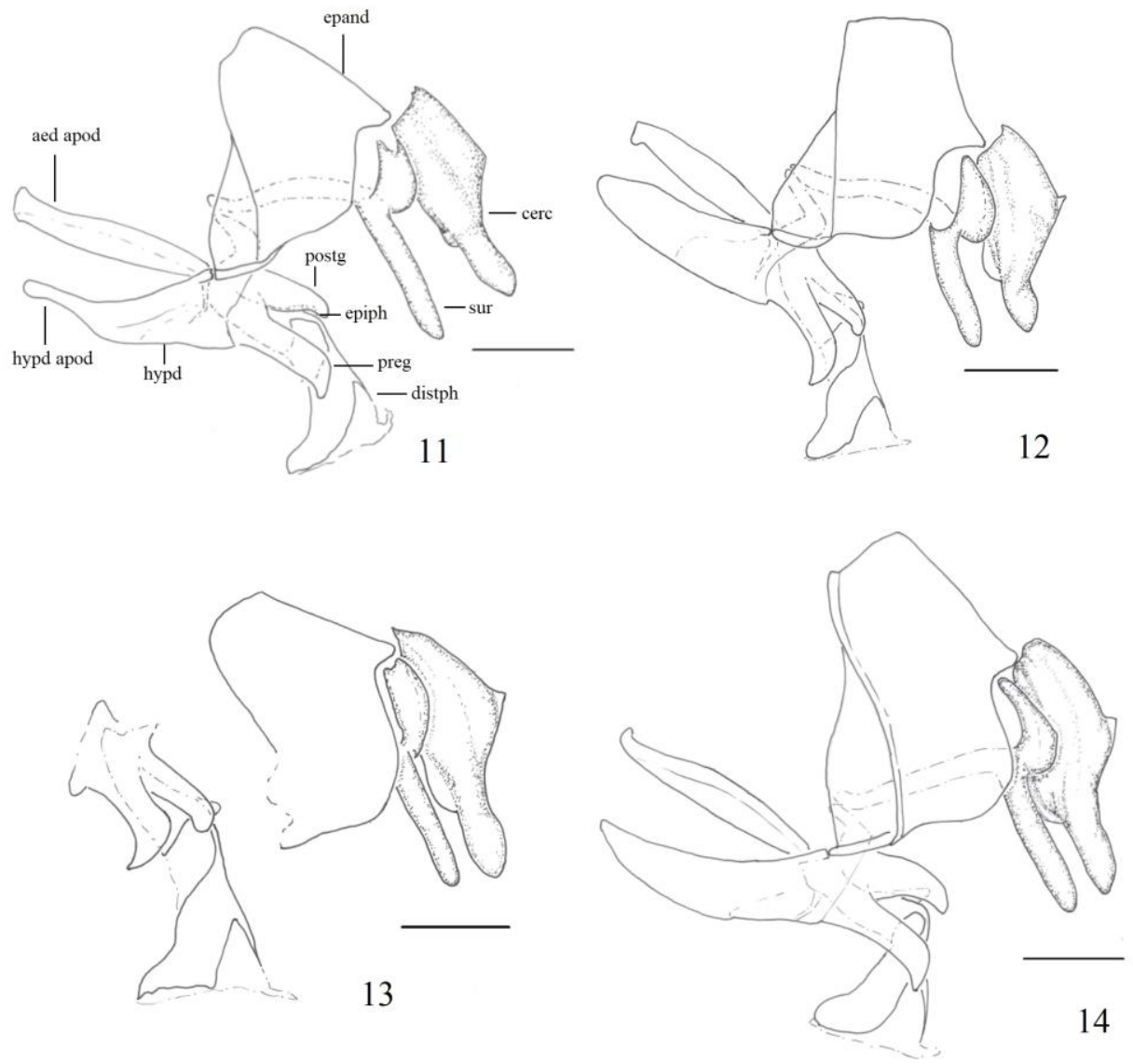

Figures 9-14. 9, Sternites 5 and 6 and syntergite $7+8$ of $P$. niheii sp. n. in anterodorsal view (scale bar: $0.25 \mathrm{~mm}$ ). 10 , Hypandrium of $P$. niheii sp. $\mathrm{n}$. in posteroventral view (scale bar: $0.25 \mathrm{~mm}$ ). $11-14$, Male terminalia in lateral view (scale bar: $0.25 \mathrm{~mm}$ ): 11, P. paraguayensis; 12, P. niheii sp. $\mathrm{n}$.; 13, P. punensis $\mathrm{sp} . \mathrm{n}$.; 14, P. rondonensis $\mathrm{sp} . \mathrm{n}$. (abbreviations: aed apod, aedeagus apodeme; cerc, cercus; distph, distiphallus; epand, epandrium; epiph, epiphallus; hypd, hypandrium; hypd a, hypandrium arm; hypd apod, hypandrium apodeme; postg, postgonite; preg, pregonite; st 5 , sternite 5 ; st 6 , sternite 6 ; sur, surstylus; syntgst $7+8$, syntergite $7+8$ ). 


\section{Proparachaeta niheii sp. n.}

(Figures 3, 4, 9, 10, 12, 16)

Type material. Holotype male (MZUSP), labelled: "SISBIOTA - CNPq - FAPESP [in lateral] / BRASIL: MT: Chap. dos Guimarães / Cachoeira Véu da Noiva / S 15²4' 21.1" W 055 50' 11" / Malaise 36 / 1622.i.2012 / Lamas, Nihei \& eq col."; "Proparachaeta niheii / Holotype [red label, species name handwritten]". [Holotype in good condition except for colouration not well preserved].

Paratypes. one male (MZUSP): "SISBIOTA - CNPq - FAPESP [in lateral] / BRASIL: MT: Chap. dos Guimarães / PN Chapada dos Guimarães / S 15² 24' 21.8" W 055 50' 07.5" / Malaise 22.xii.2011-17.i. 2012 / Lamas, Nihei \& eq col."; "Proparachaeta niheii / Paratype [red label, species name handwritten]". One male (MZUSP): "SISBIOTA - CNPq - FAPESP [in lateral] / BRASIL: MT: Chap. dos Guimarães / PN Chapada dos Guimarães / S 15²4' 30.0" W 055 49' 59.9" / Coleta Manual (rede) / Trilha Véu da Noiva / 16.i.2012 / Lamas, Nihei \& eq col."; "Proparachaeta niheii / Paratype [red label, species name handwritten]".

Diagnosis. Head yellow pruinose or silvery grey when viewed from certain angles; ocellar setae weak almost not differentiated from ocellar triangle setulae; scutellar dorsum brown with brown pruinosity; calypters yellow with light brown pruinosity; abdomen dark brown in ground colour (or dark brown with sides reddish-brown in one specimen) with tergites 3 and 4 each with irregular band of grey pruinosity on anterior fifth and faint light brown pruinosity posteriorly in posterodorsal view; tergite 5 with yellow pruinosity, denser ventrally; syntergite $1+2$, tergites 3 and 4 each with a spot of dense grey pruinosity on midventral margin in posteroventral view.

Male description. Body length: $13.2-14.7 \mathrm{~mm}$; wing length $12.2-12.5 \mathrm{~mm}$. Coloration. Vertex and frontal vitta dark brown with brown pruinosity; ocellar triangle black with brown pruinosity; head covered with yellow pruinosity or silvery grey from certain angles; lunule and scape reddish-brown; pedicel and first flagellomere dark brown with brown pruinosity; palpus and proboscis dark brown; thorax dark brown in ground colour except scutum laterally and postalar callus brown; pruinosity on thorax yellowish-grey to brownish-grey, except postpronotal lobe, scutum laterally and anepisternum yellower; scutellar dorsum brown with brown pruinosity; legs dark brown; wing hyaline with brown veins; wing stalk light brown basally and brown distally; calypters yellow with light brown pruinosity, with very short hairs of the same colour on margin; abdomen dark brown in ground colour (dark brown with sides reddish-brown in one specimen); tergites 3 and 4 each with irregular band of grey pruinosity on anterior fifth and faint light brown pruinosity posteriorly in posterodorsal view; tergite 5 with yellow pruinosity, denser ventrally; syntergite $1+2$, tergites 3 and 4 each with a spot of dense grey pruinosity on midventral margin in posteroventral view. Head. Vertex about $0.24 \mathrm{x}$ head width in dorsal view; inner vertical seta and reclinate orbital seta missing in the material examined; ocellar seta weak almost not differentiated from ocellar triangle setulae; frontoorbital plate with about 12 frontal setae, upper seta slightly stronger than fronto-orbital setulae, one or two setae situated below lower margin of pedicel; fronto-orbital plate slightly narrower than parafacial; first flagellomere about $1.3 \mathrm{x}$ length of pedicel; pedicel about $2.8 \mathrm{x}$ length of scape; third aristomere about $1.9 \mathrm{x}$ length of first flagellomere; facial ridge with row of stout supravibrissal setae on lower 0.4 of its length, setae $0.2-0.46 x$ length of vibrissa; anteroventral margin of gena with a row of setae extending backward, setae $0.26-0.4 x$ length of vibrissa. Thorax. Acrostichal setae $3+3$, with posteriormost postsutural seta longer and about $1.7 x$ length of the preceding seta; dorsocentral setae $3+4$, with posteriomost postsutural seta longer and about $1.54 x$ length of the preceding seta; intra-alar setae $2+3$, with posteriormost postsutural seta longer and stronger and about $2.4 \mathrm{x}$ length of the preceding seta; apex of the posteriormost presutural intraalar seta not reaching insertion of the first postsutural intra-alar seta; supra-alar setae $1+3$, with the second and third postsutural setae longer, each about 1.7x length of first postsutural seta; three postalar setae, second seta longer and stronger, about $1.85 \mathrm{x}$ length of the third seta; katepisternum with four to six setae [number of setae can vary on each side of body in a single specimen]: the anterior and posterior katepisternal setae 
[always present] longer and stronger; one or two anteroventral setae, one more ventral [rarely present], stouter and close to anterior katepisternal seta, the other anteroventral seta weak; one or two posteroventral setae almost aligned with anterior and posterior katepisternal setae; scutellum usually with one pair basal, three pairs of lateral, one pair of subapical, one pair of apical [little longer than setulae on the scutellar dorsum], one or two discal pairs of setae; mid tibia with three strong anterodorsal setae, the longest seta about $0.3 \mathrm{x}$ length of tibia; hind tibia with an irregular row of posterodorsal setae, the longest seta is shorter than the longest seta of the anterodorsal row. Terminalia (Figs. 9, 10, 12, 16). Epiphallus short; cercus in profile anteriorly almost straight in the basal two-thirds, gently curved backward subapically, with anterior protuberance between cerci well-developed, posteriorly convex on basal half, slightly excavated at the apical two-thirds and rounded subapically; cerci in posterior view subtriangular, with lateral edges slightly convex.

Female. Unknown.

Etymology. The specific epithet was chosen in honour of Silvio Nihei, dipterist at the Instituto de Biociências da Universidade de São Paulo, Brazil.

Geographic distribution. Brazil (Mato Grosso).

Remarks. See remarks section of $P$. paraguayensis.
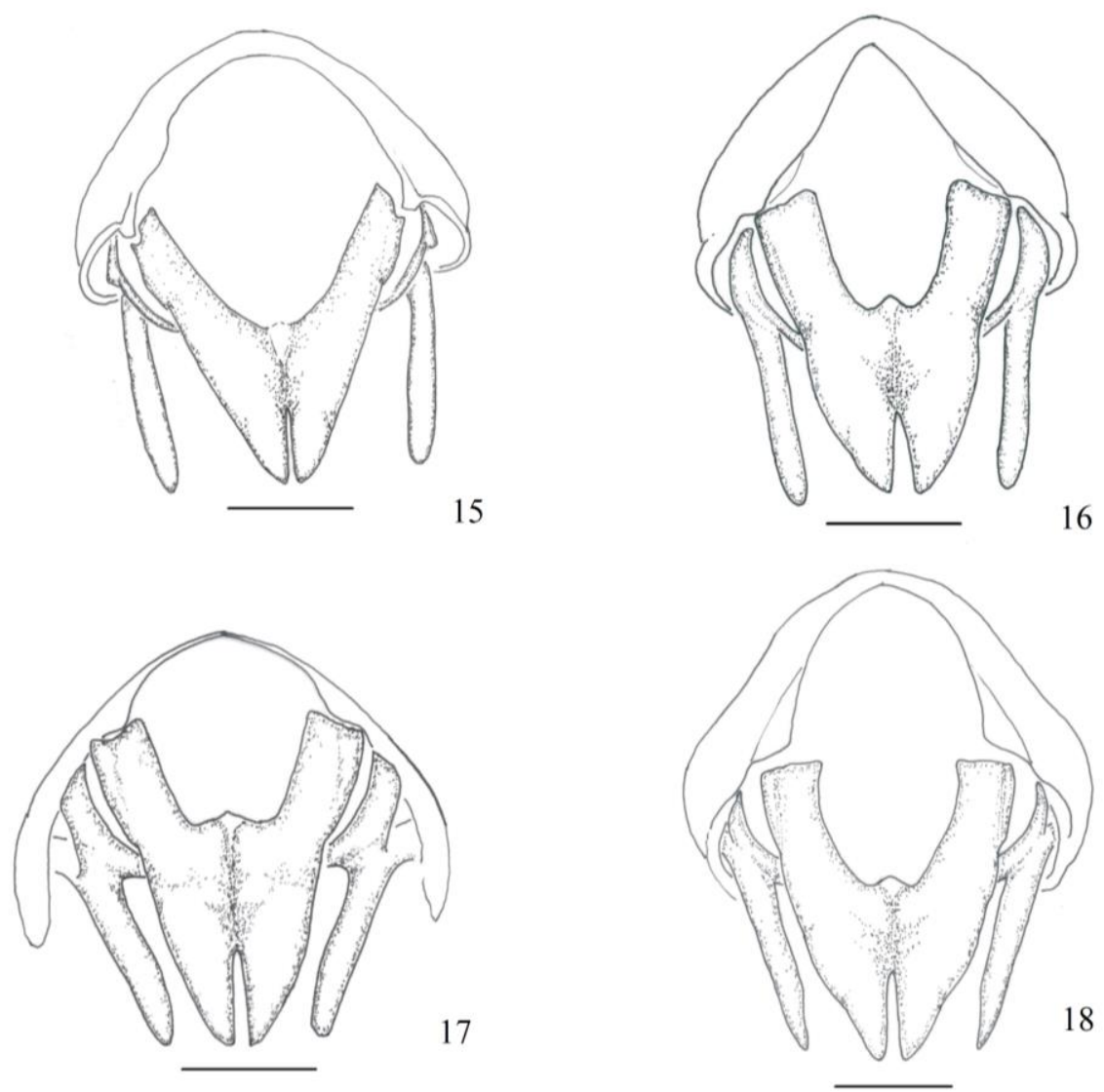

Figures 15-18. Male terminalia in posterior view (scale bar: $0.25 \mathrm{~mm}$ ): 15, P. paraguayensis; 16, P. niheii sp. n.; 17, P. punensis sp. n.; 18, P. rondonensis sp. $\mathrm{n}$. 


\section{Proparachaeta punensis sp. $\mathbf{n}$.}

(Figures 5, 6, 13, 17)

Type material. Holotype male (MZUSP), labelled: "Casa Huiri / Peru 4500 ft"; "4.ii [?].10 [handwritten]"; "CHT Townsend / coll"; "Proparachaeta / paraguayensis T. / J. H. Guimarães [misidentification, 'Proparachaeta paraguayensis T.' handwritten]"; "Proparachaeta punensis / Holotype [red label, 'Proparachaeta punensis' handwritten]". [Left midleg and right hind leg missing, parts of other legs except left foreleg damaged, abdomen damaged when dissected].

Diagnosis. Head yellow pruinose; four postsutural supra-alar setae; ratio of the posteriormost acrostichal, dorsocentral and intra-alar setae length and their respectively preceding setae relatively shorter compared to the other species; calypters yellow with light yellow pruinosity; abdomen dark brown in ground colour except laterally lighter; tergite 3 in posterodorsal view with irregular band of grey pruinosity on anterior fifth and faint brown pruinose posteriorly; tergite 4 with irregular band of yellowish-grey pruinosity on anterior fifth and brown pruinose posteriorly; tergite 5 yellow pruinose.

Male description. Body length: $13.2 \mathrm{~mm}$; wing length $12.2 \mathrm{~mm}$. Coloration. Vertex and frontal vitta brown; ocellar triangle black with greyish-yellow pruinosity; head covered with yellow pruinosity; occiput with pale cream-coloured hairs; lunule yellow; scape yellowish-brown; pedicel and first flagellomere dark brown with brown pruinosity; palpus and proboscis light brown; thorax dark brown in ground colour except postpronotal lobe, scutum laterally, postalar wall brown; scutellar dorsum brown with brown pruinosity, except sides greyish-brown; legs dark brown; wing hyaline with light brown veins; wing stalk yellow basally; calypters yellow with light yellow pruinosity, with very short hairs of same colour on margin; abdomen dark brown in ground except laterals brown; tergite 3 in posterodorsal view with irregular band of grey pruinosity on anterior fifth and faint brown pruinose posteriorly; tergite 4 with irregular band of yellowish-grey pruinosity on anterior fifth and brown pruinose posteriorly; tergite 5 yellow pruinose; syntergite $1+2$ and tergites 3 and 4 each with a subtriangular spot of silvery grey pruinosity on midventral margin in posteroventral view. Head. Vertex about $0.25 \mathrm{x}$ head width in dorsal view; inner vertical seta stout and curved backward, about $1.5 x$ length of reclinate orbital seta; ocellar seta short and thin but can be differentiated from ocellar triangle setulae; fronto-orbital plate with about 12 frontal setae, uppermost seta slightly stronger than fronto-orbital setulae; frontal setae ending just below lower margin of pedicel; frontoorbital plate slightly narrower than parafacial; first flagellomere about $1.5 x$ length of pedicel; pedicel about $2.85 \mathrm{x}$ length of scape; third aristomere about $1.6 \mathrm{x}$ length of first flagellomere; facial ridge with row of stout supravibrissal setae on lower half of its length, setae $0.35-0.45 x$ length of vibrissa; anteroventral margin of gena with a row of setae extending backward, setae $0.3-0.45 \mathrm{x}$ length of vibrissa. Thorax. Acrostichal setae $3+3$, with posteriormost postsutural seta longer and about $1.4 \mathrm{x}$ length of the preceding seta; dorsocentral setae $3+4$, with posteriomost postsutural seta longer and about $1.45 \mathrm{x}$ length of the preceding seta; intra-alar setae $2+3$, with posteriormost postsutural seta longer and stronger, about $1.8 x$ length of the preceding seta; apex of the posteriormost presutural intra-alar seta reaching insertion of the first postsutural intra-alar seta; supra-alar setae $1+4$, with the second, third and fourth postsutural supra-alar setae almost the same size, each about $1.3 \mathrm{x}$ length of first postsutural seta; three postalar setae, the second seta longer and stronger, about 2.1x length of the third seta; katepisternum with five or six setae [number of setae varies on each side of the body]: the anterior and posterior katepisternal setae longer and stronger, one anteroventral seta, two posteroventral setae aligned with anterior and posterior katepisternal setae and one apparently unusual seta in front of anterior katepisternal seta; scutellum with one basal, three lateral, one subapical, one tiny apical and two discal pairs of setae. Terminalia (Figs. 13, 17). Pregonite more spatulate than in other species; epiphallus short; cercus in profile almost straight and slightly rounded subapically, with protuberance between cerci in the midlength well-developed, posteriorly slightly concave in the middle and rounded subapically; cerci in posterior view subtriangular, with lateral edges slightly convex.

Female. Unknown. 
Etymology. The specific epithet refers to the province of the type locality of this species (Puno, Peru).

\section{Geographic distribution. Peru (Puno).}

Remarks. Proparachaeta punensis sp. n. is the only species with four postsutural supra-alar setae.

\section{Proparachaeta rondonensis sp. $\mathbf{n}$.}

(Figures 7, 8, 14, 18)

Type material. Holotype male (MZUSP), labelled: "SISBIOTA - CNPq - FAPESP [in lateral] / BRASIL: RO: Monte Negro [correct locality: Campo Novo de Rondônia] / Fazenda Amorim - 248 m / S 10 40' 6" W 63 29'0" / Malaise trap 6m / 03-15.xii.2011 / Amorim, Ament \& Riccardi cols"; "Proparachaeta rondonensis / Holotype [red label, species name handwritten]. [Holotype in good condition except for some setae missing].

Paratype. One male (MZUSP): "SISBIOTA - CNPq - FAPESP [in lateral] / BRASIL: RO: Monte Negro [correct locality: Campo Novo de Rondônia] / S1040'6" W63²9'0" / Malaise trap 6-248m / 03-15.xii.2011 / Amorim, Ament \& Riccardi cols"; "Proparachaeta rondonensis / Paratype [red label, species name handwritten]".

Diagnosis. Head with moderate yellowish-grey pruinosity; calypters brown with brown pruinosity; the longest anterodorsal seta of mid tibia about $0.2 \mathrm{x}$ of tibia length; abdomen dark brown in ground colour with brown pruinosity more visible on tergite 5 ; in posteroventral view, tergites 3 and 4 each with weak spot of pale brown pruinosity on midventral margin.

Male description. Body length: 13.6-13.9 mm; wing length 11.9-12.7 mm. Coloration. Vertex and frontal vitta dark brown with brown pruinosity; ocellar triangle black with greyish-brown pruinosity; head covered with moderate yellowish-grey pruinosity; occiput with pale cream-coloured hairs; lunule and scape reddishbrown; pedicel and first flagellomere dark brown with brown pruinosity; palpus reddish-brown; proboscis brown; thorax dark brown in ground colour except scutum laterally and postalar callus brown; thorax grey pruinose except postpronotal lobe and postalar wall yellowish-grey, scutum laterally yellow; scutellar dorsum dark brown with brown pruinose; legs dark brown; wing hyaline with light brown veins; calypters brown with brown pruinosity, with very short hairs of the same colour on margin; abdomen dark brown in ground colour with brown pruinosity more visible on tergite 5; tergites 3 and 4 each with a weak spot of pale brown pruinosity on midventral margin in posteroventral view. Head. Vertex about $0.3 \mathrm{x}$ head width in dorsal view; inner vertical seta stout and curved backward, about $1.5 \mathrm{x}$ length of reclinate orbital seta; ocellar seta weak almost not differentiated from ocellar triangle setulae; fronto-orbital plate with about 13 frontal setae, upper seta slightly stronger than fronto-orbital setulae; frontal setae ending just before lower margin of pedicel; fronto-orbital plate slightly narrower than parafacial; first flagellomere about 1.3x length of pedicel; pedicel about 2.95x length of scape; third aristomere about 1.8x length of first flagellomere; facial ridge with row of stout supravibrissal setae on lower 0.4 of its length, setae $0.3-0.5 x$ length of vibrissa; anteroventral margin of gena with row of setae extending backward, setae $0.3-0.4 x$ length of vibrissa. Thorax. Acrostichal setae $3+3$, with posteriormost postsutural seta longer and about $1.7 x$ length of the preceding seta; dorsocentral setae $3+4$, with the posteriomost postsutural seta longer and about twice length of the preceding seta; intra-alar setae $2+3$, with apex of the posteriormost presutural intra-alar seta not reaching insertion of the first postsutural intra-alar seta; the posteriormost postsutural intra-alar seta longer and stronger, about $2.2 \mathrm{x}$ length of the preceding seta; supra-alar setae $1+3$, with the second and third posteriormost postsutural setae longer, each about twice length of first postsutural seta; three postalar seta, the second seta longer and stronger, about twice length of the posteriormost seta; katepisternum with three setae: one anterior and one posterior katepisternal setae longer and stronger and one anteroventral seta; 
scutellum with one pair of basal, three or four pairs of lateral, one pair of subapical, one pair of apical [little longer than setulae on the scutellar dorsum] and one discal pair of setae; mid tibia with two or three strong anterodorsal setae, the longest seta about $0.2 x$ length of tibia; hind tibia with an irregular row of posterodorsal setae, the longest seta longer than the longest seta of the anterodorsal row. Terminalia (Figs. 14, 18). Epiphallus short; cercus in profile anteriorly almost straight in the basal half, with anterior protuberance between the cerci in the midlength well-developed, posteriorly slightly convex on basal half and rounded subapically; cerci in posterior view subtriangular, with lateral edges slightly convex.

Female. Unknown.

Etymology. The specific epithet refers to the state of the type locality of this species (Rondônia, Brazil).

Geographic distribution. Brazil (Rondônia).

ACKNOWLEDGMENTS. I am grateful to Silvio Nihei (Instituto de Biociências - USP) and Carlos Lamas (Museu de Zoologia - USP) for loaning material and for support through the SISBIOTA-Diptera Project (CNPq Process number 563256/2010-9, FAPESP Process number 2010/52314-0). Silvio Nihei, James O'Hara (CNC) and Daniel Whitmore (State Museum of Natural History, Stuttgart) generously provided comments and suggestions on an earlier draft of the manuscript. I thank Frank Menzel (Deutsches Entomologisches Institut) for loaning the holotype of Proparachaeta paraguayensis. Finally, my thanks to Kenji Toma and Zoraida Fernández for graciously reviewing an early draft of the manuscript and James R. Welch for English language review.

\section{LITERATURE CITED}

Cerretti, P., O’Hara, J. E., Wood, D. M., Shima, H., Inclán, D. J., Stireman, J. O. III. (2014) Signal through the noise? Phylogeny of the Tachinidae (Diptera) as inferred from morphological evidence. Systematic Entomology, 39, 335-353.

DOI:10.1111/syen.12062

Cumming, J. M., Wood, D. M. (2017) 3. Adult morphology and terminology, pp. 89-133. In: KirkSpriggs, A. H., Sinclair, B. J. (Eds.). Manual of Afrotropical Diptera, vol. 1. Suricata 4. South Africa National Biodiversity Institute, Pretoria.

Guimarães, J. H. (1971) 104. Family Tachinidae, pp. 1-333. In: Papavero, N. (Ed.). A catalogue of the Diptera of the Americas south of the United States. Museu de Zoologia, Universidade de São Paulo, Brasil, São Paulo.

Guimarães, J. H. (1977) Host-parasite and parasite-host catalogue of South America Tachinidae (Diptera). Arquivos de Zoologia, 28, 1-131.

Herting, B. (1984) Catalogue of Palearctic Tachinidae (Diptera). Stuttgarter Beiträge zur Naturkunde, Serie A (Biologie), 369, 1-228.

O'Hara, J., Wood, D. W. (2004) Catalogue of the Tachinidae (Diptera) of America North of Mexico. Memoirs on Entomology, International, 18, 1-410.

Toma, R., Guimarães, J. H. (2000) Revisão do gênero Proparachaetopsis revalidado (Diptera, Tachinidae). Iheringia - Série Zoologia, 88, 15-24.

Toma, R., Guimarães, J. H. (2002) Estudo taxonômico de Leschenaultia Robineau-Desvoidy (Diptera, Tachinidae). Revista Brasileira de Entomologia, 46, 33-70.

DOI:10.1590/S0085-56262002000100006

Toma, R., Nihei, S. S. (2006) Catálogo do material-tipo de Tachinidae (Diptera) depositado no Museu de Zoologia da Universidade de São Paulo. Revista Brasileira de Entomologia, 50, 240-256.

DOI:10.1590/S0085-56262006000200006 
Townsend, C. H. T. (1928) New muscoidea from humid tropical South America. Wiener Entomologische Zeitschrift, 44, 143-154.

Townsend, C. H. T. (1936) Manual of Myiology, in twelve parts. Part IV: Oestroid classification and habits (Dexiidae and Exoristidae). Charles Townsend \& Filhos, Itaquaquecetuba, Brasil, 303 pp.

Townsend, C. H. T. (1941) Manual of Myiology, in twelve parts. Part XI: Oestroid generic diagnosis and data (Goniini to Trypherini). Charles Townsend \& Filhos, Itaquaquecetuba, Brasil, 330 pp.

Tschorsnig, H. P. (1985) Taxonomie forstlich wichtiger Parasiten: Untersuchungen zur Struktur des männlichen Postabdomens der Raupenfliegen (Diptera, Tachinidae). Sturttgarter Beiträge zur Naturkunde - Serie A (Biologie), 383, 1-137.

Wood, D. M. (1987) Tachinidae, pp. 1193-1269. In: McAlpine, J. F., Peterson, B. V., Shewell, G. E., Teskey, H. J., Vockeroth, J. R., Wood, D. M. (Eds.). Manual of Nearctic Diptera, vol. 2. Agriculture Canada Monograph, 28. 